\title{
The Encoding of Field in EFL Learners' Academic Writing in English
}

\author{
Budi Rahayu ${ }^{1}$ \\ ${ }^{1}$ Cenderawasih University, Indonesia \\ Correspondence: Budi Rahayu, Cenderawasih University, Indonesia.
}

Received: January 26, 2021; Accepted: February 12, 2021; Published: March 2, 2021

\begin{abstract}
One of the problems in teaching English as a foreign language (EFL) is the teachers' lack of knowledge on the process of the students' text production, which seems to have not been adequately explored and described. This research aims to describe the process of encoding of Field in EFL learners' academic writing in English, especially argumentative texts, focusing on how students produce the texts and why they produce the texts as they do. A Mixed method is applied in this research; Qualitative data is collected from interviews and quantitative data is compiled from the texts produced by a group of 25 Indonesian university students, who become the subject of this research. The findings show that Indonesian students, when writing English argumentative texts, use mostly Material process, Relational process, and Mental process. Furthermore, the students mostly use Circumstance of Reason, Time and Circumstance of Degree. These types of Processes and Circumstances are encoded in the text for the reasons of elaborating, explaining, and expressing opinions, based on the question asked. In other words, the encoding of Field seems to be influenced by the question or prompt given. This has given an idea of how foreign language teaching should be conducted.
\end{abstract}

Keyword: field, encode, academic writing, Indonesian students

\section{Introduction}

There are many ways or methods of teaching English as a foreign or second language. For example, Diane LarsenFreeman (2000) mentions some. They are the grammar-translation method, the direct method, the audio-lingual method, the silent way, desuggestopedia, community language learning, total physical response, communicative language teaching, content-based, task-based, and participatory approaches. Each of these methods has its specific characteristics and therefore appropriate to be used under certain conditions. One of the conditions that teachers need to know is the condition of learners, and to limit the scope of this study, the learner language. Understanding learner language can be very useful for teachers to apply certain teaching methods or teaching procedures (Lightbown \& Spada, 1999).

Teaching English as a foreign language (EFL) has been widely explored and discussed by many scholars around the globe. For example, some researchers investigate EFL teachers' competency in teaching (e.g.: Rinantani, Asfah, Atmowardoyo, Bin-Tahir, 2017), some investigate the tasks in EFL (e.g.: Lee, 2018), some explore vocabulary learning in EFL (e.g. Bensalem, 2018), some have investigated the role of multiple intelligences in EFL learning (Rahayu, 2020), and many others. However, research on the process of text production by EFL learners seems to have not been adequately investigated and needs to be given attention.

Although much research on EFL has been widely explored and discussed, however, English proficiency is still a problem for Indonesian students (Renandya, Hamied, Nurkamto, 2018). Research on the TOEFL score of Cenderawaish university students by Budi Rahayu (2020), for instance, has provided evidence for this claim. This problem can be caused by many factors. This may be caused by the learners themselves or by teachers. Therefore both reasons need to be discussed, and in this research, the final and general purpose is to provide teachers with knowledge of understanding learner language or linguistic features and how these features are produced for them to be able to apply any appropriate teaching methods in a classroom.

The students' linguistic features are related to how the students encode what they mean in a text. What the students mean encoded in a text includes three dimensions of contexts: the subject matter (Field), the attitude (Tenor), and the organization (Mode). These three dimensions of context are fused to form a specific register. Some studies on Mode and Tenor in foreign or second languages have been conducted (e.g. Rahayu, 2014). However, studies on the encoding of Field, especially by foreign language learners, have not been adequately conducted yet. This study focuses on Field, that is, how Indonesian students, represented by Cenderawasih University students, encode the 
subject matter in their academic writing in English as a foreign language. The question that needs to be answered in this research is how and why Field is encoded by Indonesian university students in their argumentative essay in English. The Field can be explained in more detail in the following:

\section{Field}

The Field is seen as the realization of experiential meaning. The definition of the Field varies. Halliday (1985, p. 12) gives the definition of Field as what is someone doing in a specific social context. it is also explained by Eggins (1994) as the topic of a talk. Bateman and Mathiesen (1991, p. 72) describe Field as a "socially significant action". Yet, another definition of Field is "what is to be talked or written about" (Butt, Fahey, Feez, Spinks, 2012, p. 23). From the various definitions, the last definition "what to be talked or written about" seems to be easily understood. Therefore, the definition of Field in this study has referred to this last definition, simplified as "the subject matter". The subject matter or Field, as well as the purpose of producing the texts, motivate the choice of grammar to realize experiential meaning (---, p.102).

The Field is an abstract concept in the context. To be able to be thought, felt, or measured, the Field needs to be realized or encoded in linguistic forms in a text. The encoding of the Field in the linguistic form is done through the system of transitivity (Halliday, 1994). This system is concerned with Participants, Processes, and Circumstances. Figure 1 summarises the concept, then is explained in detail in the sections following it.

\section{Realised in}

CONTEXT $\longrightarrow$ TEXT

\begin{tabular}{|l|l|}
\hline \multirow{2}{*}{$\begin{array}{l}\text { FIELD: } \\
\text { discourse }\end{array}$} & $\begin{array}{l}\text { TRANSITIVITY: } \\
\text { Participants: Nominal groups }\end{array}$ \\
\cline { 2 - 3 } & $\begin{array}{l}\text { Processes: Verbal groups } \\
\text { Circumstances: } \\
\text { Adverbial groups or prepositional phrases }\end{array}$ \\
\hline
\end{tabular}

Figure 1. The Realisation of Field in Text

Figure 1 shows how Field is realized in texts, in the form of Participants, Processes, and Circumstances. The details are explained in the following sections.

\subsection{Participants and Processes}

Participants and Processes are discussed in the same section here because the Participants and Processes are associated. The types of Participants and Processes depend on each other. Material Processes, for instance, are associated with the Participants of Actor and Goal. Verbal Processes are associated with the Participants of Sayer and Verbiage.

A Participant can be marked as a noun group in the constituent of a sentence. The function of this constituent might be as a subject, direct object, indirect object, or object complement (Rubba, 2011). The Participants in a text are realized by nominal groups. Participants can be persons, places, or objects. Based on the functions, Participants are termed with various names: Actors, Sensers, Behavers, Sayers, Receivers, Verbiages, Targets, Phenomenons, Goals, Identified, Identifiers, Tokens, Values, Carriers, Attributes, and Existents (Halliday, 1994). A Process is a verb that is part of a predicate in a clause (Rubba, 2011). A Verb is defined as "that which asserts an action or state" (Stageberge \& Oaks, 2000). Additionally, Longman (2003) also defines it as "a word or group of words that describe an action, experience, or state" Furthermore, Halliday (1994, p. 106) defines Processes as 'goings-on'. From these definitions, it can be concluded that a Process is a word in a clause that indicates an action or occurrence. Following Halliday, Processes consist of Material, Mental, Behavioural, Relational, Verbal, and Existential. These types of Processes enable writers to write an idea in a way they choose, different from the others (Butt, Fahey, Feez, Spinks, 2012, p.100). These types of Processes are explained in the following paragraphs.

First, the Material process is a Process that functions to encode the world of doing and happening. In the Material Processes, Participants function as Actors, Goals, and Beneficiaries. An Actor is the one who does the action. A Goal is the one at which the Process is directed, while a Beneficiary is for whom the Process is realized. 
Examples:

\begin{tabular}{|l|l|l|}
\hline The children & are catching & a cat \\
\hline Actor & Process: Material & Goal \\
\hline
\end{tabular}

\begin{tabular}{|l|l|l|}
\hline The doctor & brought & some medicine \\
\hline Actor & Process: Material & Goal \\
\hline
\end{tabular}

Secondly, Behaviour processes are processes to encode the behavior of human being such as "cry, laugh, sing, sit, dream", and so on. In Behavioral processes, participants function as Behavers.

Examples:

\begin{tabular}{|l|l|l|}
\hline That old man & dreamt & of going to a strange place \\
\hline Behaver & Process: Behavioral & Phenomenon \\
\hline
\end{tabular}

The cute baby is crying

\begin{tabular}{l|l|l}
\hline Behaver & Process: Behavioral
\end{tabular}

Third, a Mental process is a process that encodes the world of sense: feeling, thinking, and seeing. There are three types of Mental processes: perception, affection, and cognition. In Mental processes, participants are conscious beings. They can feel, think or perceive. They function as Senser and Phenomenon. Senser includes feeling, thinking, or sensing, and phenomenon includes what is sensed, felt, thought, or viewed (Halliday, 1994).

Examples:

\begin{tabular}{|l|l|l|}
\hline I & like & Her \\
\hline Senser & Process: Affection & Phenomenon \\
\hline
\end{tabular}

\begin{tabular}{|l|l|l|}
\hline The guest & Knows & You \\
\hline Senser & Process: Cognition & Phenomenon \\
\hline
\end{tabular}

Fourth, Verbal processes are the processes encoding the world that is associated with saying. In Verbal processes, participants can function as Sayer, Receiver(Beneficiary), Verbiage (Range), and Target. Sayer is anything that gives a signal. The Receiver is one to whom the signal is directed. Verbiage is what is said and Target is the entity that is targeted by the process of saying.

Examples:

\begin{tabular}{|l|l|l|}
\hline The old woman & Told & an amazing story \\
\hline Sayer & Process: Verbal & Verbiage \\
\hline
\end{tabular}

\begin{tabular}{|l|l|l|l|}
\hline The teacher & Asked & the student & to help them \\
\hline Sayer & Process: Verbal & Receiver & Verbiage \\
\hline
\end{tabular}

Fifth, a Relational process is a process that encodes the world of being in linguistic forms. They function to relate two different entities in a clause. This process can be attributive or identifying. Attributive means that one entity has a quality attribute to it, and Identifying means that one entity identifies another entity. In Relational Processes, Participants function as Carrier or Attribute. Carrier is the entity that is ascribed, while Attribute is the quality that 
ascribes. Participants in Relational Processes can also function as Identified and Identifier. Identified is an entity that is identified and an identifier is an entity that identifies.

Examples (attributive):

\begin{tabular}{|l|l|l|}
\hline The counselor & Is & Wise \\
\hline Carrier & Process: Intensive & Attribute \\
\hline
\end{tabular}

\begin{tabular}{|l|l|l|}
\hline The experience & Is & exciting \\
\hline Carrier & Process: Intensive & Attribute \\
\hline
\end{tabular}

(identifying):

\begin{tabular}{|l|l|l|}
\hline My team & Is & the winner of the match \\
\hline Identified & Process: Attributive (identifying) & Identifier \\
\hline
\end{tabular}

\begin{tabular}{|l|l|l|}
\hline John & Is & my classmate \\
\hline Identified & Process: Intensive (Identifying) & Identifier \\
\hline
\end{tabular}

Sixth, Existential processes are processes that function to encode the existence of something. It can also be defined as "to represent that something exists or happens" (Halliday, 1994). A typical example of an Existential clause is that it does not have any subject, except an empty subject (Ping, 2004) or expletive 'there'. The word 'there' does not have any experiential meaning, only functioning to fill in the slot of a subject (Eggins, 1994, p.254). The verb in an Existential process clause is 'be'. So Existential clause structure I "There + be form + Indefinite Noun Phrase". There are also other verbs having similar meanings with 'be'. They are 'exist', 'remain', 'arise', 'occur', 'come about', 'take place' (Halliday, 1994). In Existential Processes, participants function as existent. These participants can be entities or events.

Examples:

\begin{tabular}{|l|l|l|l|}
\hline There & Is & a book & on the table \\
\hline & Process: Existential & Existent & Circumstance \\
\hline
\end{tabular}

\subsection{Circumstances}

Circumstances are the elements that function to encode the situation of a Process. The Situation here means how, where, when, what purpose, and so on, a process takes place. Laurel J. Brinton (2000, p. 191) calls it an adverb, which is "optional modifiers, both at the level of a verb phrase and the level of a sentence". Brinton then divides adverbs into three types. First are adjunct adverbials, which are manner, time, place, and reason. The second type is disjunct adverbial. This adverb modifies the whole sentence or clause and usually expresses the writers' attitude. The last type of Brinton's adverb is conjunct adverbial or conjunctive adverbs. They function to relate one clause to another. A similar idea about circumstances is from Halliday (1994). He calls circumstances the realization of 'when, where, how, why'. Halliday identifies nine types of circumstances: Extent, Location, Manner, Cause, Contingency, Accompaniment, Role, Matter, and Angle.

It seems that there are similarities and differences amongst linguists in categorizing Circumstances or Adverbs and some overlap. To accommodate the ideas, Circumstance in this research is categorized into the circumstance of time, place, manner, degree, purpose, condition, accompaniment, role, and matter.

Firstly, Circumstance of Time functions to tell when, how long or how often an action happens.

Example:

\begin{tabular}{|l|l|l|l|}
\hline I & have been writing & this book & For two years \\
\hline Actor & Process: Material & goal & Circumstance: time \\
\hline
\end{tabular}


Secondly, Circumstance of Place tells where the action happens.

Example:

\begin{tabular}{|c|c|c|}
\hline Librarians & Work & in libraries \\
\hline Behaver & Process: behavior & Circumstance: Location \\
\hline
\end{tabular}

Third, Circumstance of Manner consists of Means, Quality, and Comparison. Circumstantial of Means functions to encode the world of "how" and "what with". Circumstantial of Quality functions to encode the world of "how". Circumstantial of Comparison functions to encode the world of "what......like".

Examples:

\begin{tabular}{|c|c|c|c|}
\hline Some people & eat & noodles & with chopsticks \\
\hline Actor & Process: Material & Goal & Circumstance: Manner \\
\hline
\end{tabular}

\begin{tabular}{|c|c|c|}
\hline The smart politician & spoke & carefully \\
\hline Behaver & Process: Behaviour & Circumstance: Manner \\
\hline
\end{tabular}

\begin{tabular}{|c|c|c|}
\hline The fruit seller & Speaks & like a politician \\
\hline Sayer & Process: Verbal & Circumstance: Manner \\
\hline
\end{tabular}

Fourth, Circumstance of Degree tells about the intensity or degree of an action or situation. It is realized in the words such as 'almost', 'nearly', 'quite', 'just', 'enough', 'hardly', 'scarcely', 'completely', 'very', and 'extremely'.

Example:

\begin{tabular}{|l|l|l|}
\hline Pigeons & Fly & very high \\
\hline Behaver & Process: behavior & Circumstance: Degree \\
\hline
\end{tabular}

Fifth, the Circumstance of Reason includes Reason, Purpose, and Behalf. The Circumstance of Purpose functions to encode what causes something to happen, the intention of actions, and who the action is intended for.

Examples:

\begin{tabular}{|l|l|l|}
\hline$I$ & could not sleep & because of the noise \\
\hline Behaver & Process: Behaviour & Circumstance: Reason \\
\hline
\end{tabular}

\begin{tabular}{|l|l|l|l|}
\hline Those doctors & are coming & here & for the sick people \\
\hline Behaver & Process: Behaviour & Circumstance: Location & Circumstance: Reason \\
\hline
\end{tabular}

Sixth, Circumstance of Condition functions to encode condition, concession, and default. Condition is encoded by "if", "in case of", "in the event of" "in spite of", "despite", "in the absence of", "in default of", "although".

Examples:

\begin{tabular}{|l|l|l|}
\hline Go & to the front yard & in case of emergency \\
\hline Process: Behaviour & Circumstance: Location & Circumstance: Condition \\
\hline
\end{tabular}

\begin{tabular}{|l|l|l|l|}
\hline The music concert & was & successful & despite the heavy rain \\
\hline Carrier & Process: Intensive & Attribute & Circumstance: Contingency \\
\hline
\end{tabular}


Seventh, Circumstance of Accompaniment functions to encode the meanings of "accompanied by, not accompanied by, in addition to, as an alternative to". These meanings are encoded by prepositions such as "with, without, besides, instead of, as well as"

Examples:

\begin{tabular}{|l|l|l|}
\hline The teacher & came & with his students \\
\hline Behaver & Process: Behaviour & Circumstance: Accompaniment \\
\hline
\end{tabular}

\begin{tabular}{|l|l|l|l|}
\hline The pilot & Flew & the plane & without his mechanic \\
\hline Actor & Process: Material & Goal & Circumstance: Accompaniment \\
\hline
\end{tabular}

\begin{tabular}{|l|l|l|}
\hline The lawyer & is speaking & instead of the accused \\
\hline Behaver & Process: Behaviour & Circumstance: Accompaniment \\
\hline
\end{tabular}

\begin{tabular}{|l|l|l|l|}
\hline The thief & Stole & my bag & as well as my wallet \\
\hline Actor & Process: Material & Goal & Circumstance: Accompaniment \\
\hline
\end{tabular}

Eight, Circumstance of Role functions to encode the meanings of "as what" and "becoming". To encode the meaning of "becoming", prepositions such as "as, by way of, in the role, in the form of" are used. To encode the meaning of "becoming" prepositions such as "into" are used.

Examples:

\begin{tabular}{|c|c|c|c|c|}
\hline Australians & appointed & Julia Gillard & \multicolumn{2}{|c|}{ as the first Australian female prime minister } \\
\hline Actor & Process: Material & Goal & \multicolumn{2}{|c|}{ Circumstance: Role } \\
\hline The old car & Changed & & the traffic & into chaos \\
\hline Actor & Process: $\mathrm{N}$ & & Goal & Circumstance: Role \\
\hline
\end{tabular}

Lastly, Circumstantial of Matter functions to encode the meaning of "what about". This meaning is realized through prepositions such as "about, concerning, with reference to, of".

Examples:

\begin{tabular}{|l|l|l|}
\hline Many people & are talking & about the royal wedding \\
\hline Behaver & Process: Behaviour & Circumstance: Matter \\
\hline
\end{tabular}

How these Participants, Processes, and Circumstances are structured to encode meanings by the Indonesian university students is investigated in this research. Furthermore, how the Indonesian university students encode their meanings in a specific way can become input for teachers to prepare appropriate teaching strategies.

\section{Research Method}

Using the theoretical framework of the Systemic Functional Linguistics' Register Theory, the method used in this research was a mixed-method; using both qualitative and quantitative data. The qualitative data were collected from interviews with a group of 25 students from Cenderawasih University, Indonesia, who became the subject of this research. The interview questions mainly asked the reasons for them to compose a text as they did.

The quantitative data were collected from the texts produced by the students. The students were given a task to write an argumentative essay. The task given was related to the general topic for students. The prompt that the students need to respond to was "We are becoming increasingly dependent on computers. They are used in trades, health, public security, and even in flight. What things will they be used for in the future? Is this dependence on computers a good thing or should we be more suspicious of their benefits?"

The texts composed by the students were then analyzed by identifying, counting, and calculating the Field markers. The analysis focused on the types of Field markers that were developed from the literature review. These Field markers include Processes of Mental, of Material, of Verbal, of Behavioural, of Relational, and Existential, 
Circumstance of Time, of Place, of Manner, of Reason, of Condition, Accompaniment, of Role, of Matter, and Degree.

\section{Findings}

The encoding of the subject matter (Field) in the Indonesian students' academic writing shows that the Indonesian university students, represented by Cenderawasih university students, used all Field markers (with different proportions) to encode the subject matter in their academic writing: Processes (Material, Mental, Verbal, Behavioural, Relational, and Existential), and Circumstances (Time, Place, Manner, Reason, Condition, Accompaniment, Role, Matter, and Degree). The findings of the encoding of Field in the Indonesian students' texts are summarized in Table 1.

Table 1. The occurrence of Field in the Indonesian university students' texts.

\begin{tabular}{ll}
\hline $\begin{array}{l}\text { Types of Field markers } \\
\text { Processes }\end{array}$ & Percentage of occurrence (\%) \\
\hline Material & 36 \\
Relational & 32 \\
Mental & 16 \\
Behavioral & 11 \\
Existential & 2.7 \\
Verbal & 2 \\
\hline Circumstances & \\
\hline Reason & 24 \\
Time & 23 \\
Degree & 15 \\
Place & 13 \\
Manner & 13 \\
Accompaniment & 8.7 \\
Condition & 6.5 \\
Role & 3 \\
Matter & 2.7 \\
\hline
\end{tabular}

From Table 1, the occurrence of each type of Field markers can be identified.

The table shows the encoding of the subject matter (Field) through Process markers and Circumstance markers which vary in the Indonesian students' texts. The occurrence of the Process markers ranges from the most frequent occurrence of Material Processes (36\%) to the least frequent occurrence of Verbal Processes $(2 \%)$. The occurrence of the Circumstance markers ranges from the most frequent occurrence of the Circumstance of Reason (24\%) to the least occurrence of the Circumstance of Matter (2.7\%). So from this table, the proportions of each type of Field marker in the students' texts can be viewed. The following paragraphs explain the occurrence of the Field markers in the students' texts in more detail, the first part being the encoding of Participant and Process and the second being the encoding of Circumstances.

\subsection{The Encoding of Participants and Processes}

The encoding of Participants and Processes can be explained as the following:

Firstly, Material Processes were encoded in all 25 texts. The total markers are $36 \%$ of all process markers in the 25 texts. Some markers of these Material Processes occurred a few times, and others occurred many times. They include make, use, earn, take, connect, try, control, do, prove, create, put, give, bring, develop, choose, look for, break, brows, guarantee, finish, save, type, work, search, create, damage, decrease, bring, show, join, predict, access, learn, happen, find, modify, deny, fly, drive, conduct, erase, detect, prepare, change, edit, print, retype, get, sell, socialize, rewrite, spend, fix, prevent, play, affect, operate, loose. The Participant markers associated with Material Processes are Actor and Goal/ Range/ Beneficiary. The actor is the subject of a clause and Goal/ Range/ Beneficiary is the object. The Actors encoded in the students' texts were we, they, people, scientists, master or professor of computer, computer, researcher, they, everything in this world, it. Goal/ Range encoded are our job, money, it, typewriter, computer, blood pressure, my time, connection, our eyes, people, robot, benefits, ideas, the function of a computer, our body, internets, texts, our life, them, our earth, global warming, dignity, something, human's life, adult movies, positive effects, negative effects, video call, e-mail, knowledge, many friends, planes, 
car, disease, task, everything, laptop, our business, many songs, a lot of money, homework, information, family, our lives, our mind.

Secondly, Relational Processes were encoded in all 25 texts with a 32\% appearance of the markers. Relational Processes encoded in the student's texts were marked by the words based, become, have, be. These Relational Process markers, especially "be", occurred many times with its variations such as is, was, were, will be. The participants associated with Relational Process are Carrier, Attribute, Token, and Value. Carriers encoded in the students' texts were marked by the words computer, it, the use of a computer, people without computers, everything, people, the dependence on the computer, human, the benefit of a computer, we, computer and server, using a computer in any field of life, computer's function, its benefits for my lecture activity, computer progress, our life, they, everything, our earth, technology. Attributes encoded were marked by the words simple, little, impossible, possible, weak, interesting, civilized, much, more advanced, disadvantageous, important, easy, careful, older, good, dependent, true, essential, amazing, uncomfortable, progressive, useful, lazy, bad, suspicious, left behind, helpful, sophisticated, fast, visible, useless, dependent, enthusiastic, funny. Tokens encoded were marked by the words computer, it, the only thing that people should be aware of using a computer, we, the actor behind the screen, children and teenagers, Facebook and the others. Values encoded were marked by the words thing, dream, reality, finding, a machine with brain, wisdom, a tool, a good thing, a thief, main benefits, a lazy person, a good impact, a bad thing, computer, a dependence, disaster for our life, successor of this country, modern era, a work, network,

Thirdly, Mental Processes were encoded in 23 texts with 16\% appearance. The markers were: think, agree, need, see, seem, ease, mean, know, imagine, like, love, hope, ignore, realize, prefer, wonder, believe, guess, suppose, observe, want, feel, look, dream. Some of these Mental Process markers occurred once in the texts, while others occurred many times with a variety of tenses. The Participants associated with Mental Process are Senser and Phenomenon. Senser is the subject or who senses, and Phenomenon is the object or what is sensed. Senser markers that occurred in the students' texts were people, we, doctors, they, I, teenager, adult, children, almost everyone, and it. Phenomenon markers that occurred were that it is just a dream, its contribution to the world, patients, you, how people live now without computers, their benefits, anything, the bad effect from radiation, how our earth in the future, this earth, what things will be used in the future, that computer can only function as the helper and media, how to use it, the aims and meaning of computer, there is a more program, a computer can fly planes, someday we would not need pen and book anymore, a computer can detect any kind of disease, it, a computer is very useful to us, a computer is used in hospitals, the existence of someone, everything in the world, good and neat writing,

The Fourth Process, Behavioural Process markers, was encoded in 9 texts with an 11\% appearance of the marker. Behavioral Process was marked by the words go, help, watch, keep, depend, increase, act, stay, live, abuse, sit, progress, follow, influence, misuse, face, leave, deny, listen, work, look, play. These markers occurred in a variety of tenses. The Participants associated with Behavioural Process are Behaver and Phenomenon. Behaver encoded in the students' texts was marked by the words people, computers, I, computer use, it, and we. Phenomenon encoded were marked by the words us, the benefits of computer, every host, doctor, people's need, music, games, change.

The fifth Process is the Existential Process. The Existential Processes were encoded in 11 texts, comprising $2.7 \%$ of the appearance of the markers. The Existential Process marker was "be" with its variety of form and tenses (is, are, was). The Participant associated with an Existential Process is Existent. The Existents encoded in the students' texts were marked by the words bad effect, many things, reason, many things, more program, computer, forest, a bird in the sky, bad things, disadvantages, hand pone, many people,

The last Process, Verbal Process, was encoded in 8 texts with a $\%$ appearance of the markers. Verbal Processes were marked by the words say, chat, tell, explain, talk, and call, with their variety of tenses. The Participants associated with Verbal Process are Sayer, Receiver, and Verbiage. Sayer is who says, Receiver is who receives the message and Verbiage is what is said. The Sayer encoded in the students' texts were marked by the words $I$, they, we. The Verbiage was marked by the words that computer is important for them, that computer progress is very surprising, shop online. The Receiver was marked by the words to us.

\subsection{The Encoding of Circumstances}

The second element of Field, the Circumstances, were also all encoded and configured in the students' texts. The following paragraphs describe the occurrence of each of nine types of Circumstance markers in the Indonesian university students' texts. 
The first Circumstance is that of Reason. It was encoded in 22 texts with the occurrence of the markers being the highest, 24\%. It was marked by the words of to fly planes, to send data, to do homework, to view everything inside our body, because they don't have it, because we can find information, to fix our mistakes, to do our job, to access the internet, to search for something, to make people live easier, for saving data, for communication equipment, to help people, to interact, to reveal more knowledge, to find evidence of a crime.

The second Circumstance is Time. It was encoded in most texts (22 texts) with the occurrence of the markers being $23 \%$. Based on the List of FTM markers analyzed by decoders, it was marked by the words now, nowadays, in the future, recently, in ages, at once, sometime later, in many occasions, someday, year by year, 5 year ago, in this era, long time ago, 17 years old, developing era, today, in the beginning, whenever, before, in the past, always, first.

The third Circumstance is that of Degree. The circumstance of Degree was encoded in 19 texts with $15 \%$ of the marker's occurrence. The markers to encode the Circumstance of Degree include very, almost, extremely, -er (faster, easier, older), more, most, just, really, many, a little bit, a lot.

The fourth Circumstance is that of Place. The circumstance of Place was encoded in most texts (23) and the occurrence of the markers is $13 \%$. It was marked by the words in overseas, on tweeter, in the computer, in social networking, in the electronic board, around the house, in universities, in junior high schools, in the cashier, in Papua, in Indonesia, from a laptop, everywhere, in front of the computer, in the office, in this world, hospital, police office, in the airport, behind the screen, in human's brain, in Japan.

The fifth Circumstance is that of Manner. It was encoded in 23 texts with the marker's occurrence being 13\%. It was marked by the words by using a computer, fast, by their own hands, easily, nicely, in many ways, through the computer, quickly, by the machine, by interviewing, surprisingly, manually, one by one, functionally, by touching the screen, continuously, carefully, face to face, to each other, more and more advanced, increasingly, well, by scanning.

The Sixth Circumstance is that of Accompaniment. It was encoded in 1en (10) texts with the occurrence of the markers being $8.7 \%$. This circumstance is encoded through the words not only, with, without, such as, as well, also.

The seventh Circumstance is that of Condition. It was encoded in ten (10) texts with the occurrence of the markers being $6.5 \%$. It was encoded through the words if, because, although.

The eighth Circumstance is Circumstance of Role that was encoded in eight (8) texts. It was encoded through the words become, as, and be which comprise $3 \%$ of all markers.

The ninth Circumstance is that of Matter. The circumstance of Matter was encoded in 11 texts. The marker to encode Circumstance of Matter was about, comprising $2.7 \%$ of all markers.

The encoding of Field in the Indonesian students' texts also shows that some types of Process markers occurred more frequently than the others. Moreover, the analysis shows that three types of Processes (Mental, Material, and Relational) occurred more frequently. The other three Processes (Verbal, Behavioural, and Existential) occurred less frequently.

As an example, the following Text 1 illustrates the Material Processes that were most frequent in the text, followed by a table showing the highest frequency of the occurrence. The bold-typed words are the Process markers.

Text 1:

"Nowadays, as we know that computer is very useful to us. It can help us in many aspects such as when we get a task, which we don't know; we can search it on the internet (Google) with the computer. Today, we also see computer is used in the hospitals, it can help increase hospitals' administration, and also it helps the doctor to view everything inside our body. Many stores use a computer in the cashier to easily counting the price of things, it is used in education. The computer also is used in businesses, through the internet you can sell everything as we call "shop online'. The computer is used in many aspects to help us to do something easier, till with computer you can see the existence of someone. Many benefits you can get with a computer. The computer can show everything in the world so that you know everything in the world. Now, we are becoming increasingly dependent on computers. A nation connects to another nation with the computer. So the computer is very useful to us, I hope we still use a computer in the future. But the way to use a computer must be socialized well because nowadays many people don't know how to use a computer." 
Table 2. The encoding of Process markers in Text 1

\begin{tabular}{|c|c|c|c|}
\hline Process & Occurrence & Percentage $(\%)$ & Markers \\
\hline Material & 13 & 48 & $\begin{array}{l}\text { get, search, used, use, used, used, sell, used, get, show, connect, } \\
\text { use, socialized }\end{array}$ \\
\hline Mental & 7 & 26 & know, know, see, see, know, hope, know \\
\hline Behavioral & 3 & 11 & help, help, help \\
\hline Relational & 3 & 11 & is, become, is \\
\hline Verbal & 1 & 4 & call \\
\hline Existential & 0 & 0 & \\
\hline
\end{tabular}

From Table 2, the proportion of each type of Process marker in the student's Text 18 can be identified. The table shows that there are $48 \%$ Material Processes encoded, much more often than the other Processes (Mental, Behavioural, Relational, and Verbal).

The encoding of the second element of Field, Circumstances, shows that Circumstances were encoded in various types of markers. Some Circumstance markers occurred more than the others. Furthermore, four types of Circumstances (Place, Time, Reason, Manner, Degree) occurred more frequently in the students' texts than the other Circumstance markers.

As an example, the following Text 2 contains the Circumstances of Time and Reason which occurred more often than others, followed by a table illustrating the frequency of the Circumstance markers. The bold-typed words are the markers of Circumstances.

"As we know that computers are the important one in our activity, especially in our study. Computers help us to make good writing. I mean that good format in writing. People become interested to use the computer for their job, but some people have a problem using a computer in their activity. It happens because we have not started from the beginning to study or learn about the computer. As we know that computers always have a change in time, if we don't follow the change we will lose the knowledge about computer. I mean that how to use a computer. In the future we will find good technology more than computers, because we people always have a change in times, to be more good from the past. Technology will become the first way for us to connecting with each other in the world. The computer is good for helping us but some people use the computer for bad purpose."

Table 3. The encoding of the Circumstance markers in Text 2.

\begin{tabular}{llll}
\hline Circumstance & Occurrence & Percentage (\%) & Markers \\
\hline Time & 11 & 46 & $\begin{array}{l}\text { in our activity, in our study, in writing, in their activity, in } \\
\text { time, from the beginning, in the future, always, in time, first, } \\
\text { from the past }\end{array}$ \\
\hline Reason & 8 & 33 & $\begin{array}{l}\text { to make good writing, to use a computer, for their job, to use } \\
\text { a computer, to study, to connect, for help us, for a bad } \\
\text { purpose }\end{array}$ \\
\hline $\begin{array}{l}\text { Matter } \\
\text { Condition }\end{array}$ & 2 & 8 & $\begin{array}{l}\text { about the computer, about computer } \\
\text { if we don't follow } \\
\text { Role }\end{array}$ \\
$\begin{array}{ll}\text { Accompaniment } \\
\text { become first one way } \\
\text { with another }\end{array}$ \\
\hline
\end{tabular}

From Table 3, the proportion of each type of Circumstance marker in the student's Text 2 can be identified. The table shows that the markers of Circumstance of Time occurred the most $(11-46 \%)$ in the text. The markers of Circumstance of Reason ranked the second (8-33\%) while all the other markers are much fewer in number.

\section{Discussion}

It has been explained that Cenderawasih University students, Indonesia, encoded and configured the subject matter in their mind (Field) through all types of Processes, mainly through Mental, Material, and Relational Processes, and through all types of Circumstances, mainly through those of Place, Time, Reason, and Manner. Why they encoded the Field like these is explained in the following. 


\subsection{Material Processes}

The typical encodings of Material Processes in Cenderawasih university students' academic writing indicate that when composing academic texts, the students express their knowledge of what is happening or what one is doing with computers. Material Processes are said to function to encode the world of doing and happening (Halliday, 1994). As a result of the students' expression of their knowledge of what is happening or what one is doing with a computer, the texts produced contained many words that indicate what is happening or what one is doing with computers. This might be related to the question addressed, viz. the use of a computer. So the Material Process markers configured in the students' texts were much influenced by the question addressed. This gives evidence that the question is the potential resource for developing texts and therefore can become a valuable resource in foreign language teaching.

\subsection{Relational Processes}

The typical encodings and configurations of Relational Processes indicate that when composing academic texts, the students relate one thing to another: They label something with attributes or with identifications. This is relevant to the function of Relational Processes which is to relate two different entities in a clause (Halliday, 1994). The encodings of Field in the students' academic writing also show that Relational Processes are typically encoded in the beginning part of the essay. This indicates that the students begin writing academic text by identifying or attributing. The encoding of Relational Processes to begin an essay in the students' texts might be motivated by some of the students' understanding that Field should be encoded to compose texts with a clear structure of the argument. In the students' texts, the arguments started with identification. Given the nature of Relational Processes above, Relational processes seem to be important in developing academic texts. Therefore, Relational Processes can become valuable resources in teaching English as a foreign language, and therefore need to be emphasized in teaching English as a foreign language.

\subsection{Mental Processes}

The typical encoding of Mental Processes in the students' texts indicates that when composing academic texts, the students use their senses of feeling, thinking, seeing (Halliday, 1994). This might be related to the purpose of writing. The purpose of writing is said to influence the type of the text (Butt, Fahey, Feez, Spinks, 2012). The academic texts written by the students were argumentative. The purpose of the argumentative text, according to Butt, Fahey, and Yallop (1995), is to justify arguments. As a result, the texts produced by the students contained many words that indicate personal justifications or personal opinions to convince readers such as think, believe, and agree. Given the above nature of Mental Processes, it seems that Mental Processes become important aspects in academic writing, especially the ones which need a representation of opinions such as the argumentative text. Moreover, Mental processes can become resources for the teaching of English as a foreign language.

\subsection{Circumstances of Time}

The typical encodings and configurations of the Circumstance of Time indicate that when composing academic texts, the students relate the topic being discussed with time (when, how long, or how often). The Time markers used in the students' texts are mostly the time related to the future (e.g.: in the future, someday, sometime later) to tell the use of computers in the future. The students also contrast the use of computers in the future with the use of a computer at present by using the Time markers related to the present (e.g.: nowadays, now, at present). The use of the variety of Time markers might be one of the ways to develop ideas in the arguments, as one of the students' understandings is that Field should be encoded to develop ideas.

The use of Time markers related to the future might be motivated by the students' understanding that the subject matter should be encoded to address the question. The question addressed by the students was the use of computers in the future. So the encodings of Time in the students' academic writing is one way of addressing the question.

\subsection{Circumstances of Place}

The typical encodings and configurations of the Circumstance of Place indicate that when composing academic texts, the students relate the topic being discussed with places. The Circumstance of Place encoded in the students' texts include general places (e.g. in this world, in our country) and more specific places (e.g.: in office, on internet, airport, and harbor). General places were used to tell the use of computers in general, and specific places were used to tell the use of computers in more specific places. The use of a variety of places, specifically the specific ones, might be motivated by the students' understanding that Field should be encoded to develop ideas. The more places were encoded, the more developed the ideas were. So the use of places in the students' academic writing is one of the ways to develop ideas in the texts. 


\subsection{Circumstances of Reason}

The typical encodings of the Circumstances of Reason in the students' academic writing indicate that when composing academic texts, the students explain what causes something to happen, or the intention of actions, or who the action is intended for (Halliday, 1994). The encoding of the Circumstance of Reason in the students' texts was related to the use of computer in a variety of fields such as to fly planes, to send data, to do homework, to view everything inside our body, to fix our mistakes, to do our job, to access the internet, to search for something, to make people lives easier. This typical encoding of the Circumstance of Reason in the students' texts might be motivated by two students' perceptions. First is the students' perception that Field in academic writing should be encoded to compose complete arguments. A complete argument, according to the students, should consist of explanations, reasons, and examples. The second students' perception is that Field should be encoded to develop ideas. By giving reasons, the arguments can develop further.

\subsection{Circumstances of Manner}

The typical encoding of the Circumstance of Manner in the students' academic writing indicates that the students, when writing academic texts, relate the topic with how something happens, with what something is done, or what is something like (Halliday, 1994). In the students' texts, the Circumstances of Manner were used to tell something related to how computers are useful (e.g.: effectively, easily, fast), to tell computers as a means to do something (e.g.: with a computer, by using a computer system, through the internet), and to compare something (e.g.: like a human being, like a place). The typical encoding of the Circumstance of Manner might be motivated by some of the students' understanding that Field should be encoded to compose complete arguments. One of the ways to compose complete arguments is to write about how something happens.

\subsection{Circumstances of Degree}

The typical encoding of the Circumstance of Degree in the students' academic writing indicates that the students, when writing academic texts, relate the topic with the extent of an action or situation (Alexander, 2005). In the students' text the Circumstance of Degree were used to tell the intensity of something related to the use of the computer (e.g.: very, almost, so, extremely), and to compare something related to the use of computers (e.g.: easier, better, smarter). The typical encoding of the Circumstance of Degree in the students' texts might be influenced by the purpose of the argumentative text that is to justify argument (Butt, Fahey, Yallop, 1995). In the students' texts, the Circumstance of Degree was used to convince the readers of the benefits of using computers.

\section{Conclusion and Suggestion}

To conclude, the analysis and discussion show that the students encode Field by referring to the prompt or question exposed to them. They combine all Field markers to develop an argument, to express opinions, and to relate facts. Furthermore, they use specific markers more than the other markers to encode Field. This might be related to the question addressed. The question addressed in this research prompts students to argue, so they use many Mental process markers. They also use many Material process markers which might due to the question which prompts them to use the action verbs to explain the use of computers.

The implication for teaching English as a foreign language is that reasons for writing, therefore, are significant factors in shaping texts. This can become the basis for teaching English as a foreign or second language, implemented in designing the syllabi, teaching Materials, the teaching methods, and language assessment. Therefore it is suggested that reason for writing, as well as the reason for listening, the reason for speaking, and reason for reading is an important part of teaching English as a foreign or second language. These reasons, in the teaching practice, can be in the form of cue cards (in speaking class), pre-reading questions (in reading class), prelistening questions (in listening class), and in the form of motion (in writing class). These reasons should be given enough emphasis in teaching English as a foreign or second language. Furthermore, teachers might prefer to choose any existed, standardized methods to teach. Otherwise, they can design their own 'method' which is appropriate with the finding of this research.

\section{References}

Alexander, L. G. (2005). Longman English Grammar. London, New York: Longman

Bensalem, E. (2018). The Impact of Whatsapp on EFL Students' Vocabulary Learning. Arab World English (AWE). 9(1), 23-28. https://doi.org/10.24093/awej/vol9no1.2

Brinton, J. Laurel. (2000). The Structure of Modern English. A Linguistic Introduction. Amsterdam/ Philadelphia: John Bunjamins Publishing Company. https://doi.org/10.1075/z.94

Butt, D., Fahey, R., \& Yallop, C. (1995). Using Functional Grammar. An Explorer's Guide. Sidney: McQuarie 
University.

Butt, D., Fahey, R., Feez, S., \& Spinks, S. (2012). Using Functional Grammar. An Explorer's Guide (3 ${ }^{\text {rd }}$ ed.). South Yarra: Palgrave Macmillan.

Cambridge. (2007). IELTS. Cambridge, UK: Cambridge University Press.

Eggins, S. (1994). An Introduction to Systemic Functional Linguistics. London: Pinter Publisher.

Eggins, S. (1992). An Introduction to Systemic Functional Linguistics. London: Pinter Publisher.

Halliday, M. A. K. (1985). Context of Situation. In Halliday, M.A.K \& Hassan, Ruqaiya. Language, Context, and Text: Aspects of Language in Social-Semiotic Perspective. Victoria: Deakin University.

Halliday, M. A. K. (1994). An Introduction to Functional Grammar. London: Edward Arnold.

Lee, J. (2018). The Effects of Task Complexity and L2 Proficiency on L2 Written Performance. The Journal of Asia TEFL, 15(4), 945-958. https://doi.org/10.18823/asiatefl.2018.15.4.4.945

Lightbown, P. M., \& Spada, N. (1999). How Languages are Learned (2 $2^{\text {nd }}$ edition). Oxford: Oxford University Press.

Longman. (2003). Dictionary of Contemporary English. Essex: Pearson Education Limited.

Mathiesen, C., \& Bateman, J. A. (1991). Text Generation and Systemic-Functional Linguistics. Experiences from English and Japanese. London: Pinter Publisher.

Ping, Alvin Leong. (2004). Delimiting the Theme of the English Clause: An Inference-Boundary Account. In SKY Journal of Linguistics, 17(2004), 167-187.

Rahayu, B. (2014). Tenor in Indonesian University Students' Argumentative Text in English. Frontiers of language and Teaching, 5(1).

Rahayu, B. (2020). TOEFL Score of English Department Students, Cenderawasih University. Indonesian Journal of Languages and Linguistics, 5(1), 51-64. https://doi.org/10.30957/ijoltl.v5i1.615

Rahayu, B., \& Rinantanti, Y. (2020). The Effect of Multiple Intelligence to English Achievement of Papuan EFL Learners. The Asian EFL Journal, 27(3.2), 287-307.

Renandya, W. A., Hamied, F. A., \& Nurkamto, J. (2018). English Language Proficiency in Indonesia: Issues and Prospects. Journal of Asia TEFL, 15(3), 618-629. https://doi.org/10.18823/asiatefl.2018.15.3.4.618

Rinantanti, Y., Asfah, R. Atmowardoyo, H., \& Bin-Tahir, S. Z. (2017). Perception of Senior High School EFL Teachers in Papua, Indonesia towards Their Own Competence. Journal of Language Teaching and Research, 8(6), 1181-1189. https://doi.org/10.17507/jttr.0806.20

Rubba, Dr. Johanna. (2011). Syntax: Terms and Concepts. Clauses and their Elements. English Department (Linguistics) Cal Poly State University-San Luis Obispo. Retrieved from http://cla.calpoly.edu/ jrubba/syn/syntax_clauses.htm

Stageberge, N. C., \& Oaks, D. D. (2000). An Introductory English Grammar (5 $5^{\text {th }}$ ed.). USA: Thomson Wadsworth.

\section{Copyrights}

Copyright for this article is retained by the author(s), with first publication rights granted to the journal.

This is an open-access article distributed under the terms and conditions of the Creative Commons Attribution license (http://creativecommons.org/licenses/by/4.0/). 